\title{
$\mathrm{PC}$ 의 진동/소음 저감을 위한 쿨링홴의 동흡진장치 및 절연장치의 개발
}

\section{A Development of the Dynamic Absorber and Damper for Vibration and Noise Reduction of the Personal Computer}

\author{
정 원 영*.이 규 호*. 정 진 태† \\ Won-young Jung, Kyu-ho Lee and Jin-tai Chung \\ (2011년 1월 6일 접수 ; 2011년 3월 18일 심사완료)
}

Key Words : Dynamic Absorber(동흡진장치), Cooling Fan(쿨링홴), Vibration Reduction(진동저감), Damper (절연장치)

\begin{abstract}
The purpose of this study is reduction the vibration of the personal computer by developing the vibration absorber and damper. The eccentricity of the cooling fan causes the vibration of the computer. We designed the material properties of the vibration absorber and damper by FEM model within operation frequencies of the cooling fan. We experiment the overall analysis and system analysis by using a laser vibrometer. The result shows that the proposed dynamic absorber and damper reduce the vibration of the personal computer.
\end{abstract}

\section{1. 서 론}

현재 일반적으로 사용되고 있는 $\mathrm{PC}$ 는 다양하고 높은 수준의 멀티미디어 환경을 원하는 고객의 수 요를 맞추기 위하여 빠른 속도로 발전하여 고성능 화 되고 있다. 이러한 고성능 컴퓨터는 한 번에 여 러 가지의 높은 사양의 프로그램들을 실행시키며 빠른 연산속도로 작업을 처리해야 하므로 시스템에 과부하에 따른 열이 발생하게 되는데 그 열을 외부 로 전달시키기 위해 $\mathrm{PC}$ 내부에 쿨링홴이 장착된다. 쿨링홴과 같은 소형 회전기기는 가공오차, 축정렬 오차로 인하여 편심이 발생하게 될 뿐 아니라 쿨링

† 교신저자; 정회원, 한양대학교 기계공학과

E-mail : jchung@hanyang.ac.kr

Tel : (031)400-5287, Fax : (031)406-6964

* 한양대학교 일반대학원 기계공학과

\# 이 논문의 일부는 2009년 추계 소음진동 학술대회에서 발표되었음.
홴의 경우 오랜 기간 사용됨에 따라 홴의 내부에 발생하는 먼지와 같은 이물질로 인하여 편심이 존 재하게 된다. 회전기기의 경우 편심은 진동 및 소음 을 발생시키는 주 원인으로 시스템의 가진주파수를 증폭시키고 만약 고유진동수와 일치하게 될 경우 부품의 고장 및 파손의 원인이 될 수 있다. $\mathrm{PC}$ 의 경우 쿨링홴의 편심으로 인한 진동이 본체에 전달 되어 하드디스크와 같은 부품의 파손 고장의 원인 이 되며 진동에 의하여 발생하는 소음은 사용자에 게 심리적·정신적 불쾌감을 유발하며 작업 능률을 저하시키게 된다. 따라서 $\mathrm{PC}$ 의 진동저감을 위한 동 흡진장치 및 절연장치의 개발에 관한 연구는 장치 의 성능 및 작업환경을 개선하는 것 뿐 아니라 $\mathrm{PC}$ 의 진동에 의한 각종부품의 고장 및 파손을 줄여 데이터를 보호할 뿐 아니라 불필요한 비용을 줄일 수 있을 것이다.

진동저감을 위한 동흡진장치의 설계와 관련하여 많은 연구가 진행되어 왔다. $\mathrm{PC}$ 에 사용되는 디스크 
드라이브의 진동저감을 위한 동흡진기 설계에 관한 연구가 진행되으며 ${ }^{(1)}$ 이론적으로 디스크 드라이브를 5 자유도 모델로 정의하여 물성치에 따른 진동량의 변화를 시뮬레이션을 통하여 예측하고 동흡진장치 및 절연장치의 설계변수를 도출하기도 하였다 ${ }^{(2)}$. 또 한 디스크 드라이브의 틸팅모드를 회피하기 위한 절연장치의 설계에 관한 연구(3)도 수행되었으며 동 흡진장치를 2자유도 모델로 단순화하여 동흡진장치 의 위치에 따른 진동저감에 관한 연구를 수행하였 다 ${ }^{(4)}$. 그리고 동흡진기를 비선형 2자유도계로 모델 링하여 모드해석을 통해 동특성에 따른 강성계수를 도출하는 연구도 수행되었다(5). 광디스크 드라이브 방진마운트의 설계를 위하여 유한요소법이 사용되 기도 하였고 ${ }^{(6)}$ 수직펌프의 경우 진동을 저감시키기 위하여 실험을 통하여 가진원을 분석하고 유한요소 모델을 통하여 동흡진장치 설계를 위한 연구도 진 행되었다(7). 유한요소모델을 통해 모드해석을 수행 하여 모터의 진동을 저감하기위한 연구의 사례도 있다 ${ }^{(8)}$.

이 연구는 쿨링홴을 장시간 사용함에 따란 발생하 는 편심에 의하여 발생되는 $\mathrm{PC}$ 본체의 진동을 저감 하는데 목적을 두고 있다. 먼저 기존 쿨링홴의 작동 영역에서 쿨링홴의 진동의 주파수를 분석하여 진동 을 발생시키는 가진원을 분석하였으며 쿨링홴에 편 심이 존재하는 경우 $\mathrm{PC}$ 의 진동량을 측정하여 작동주 파수 대역에서 진동을 저감시키기 위한 동흡진장치 및 절연장치를 개발하였다. 유한요소 해석을 통하여 설계변수를 도출하였으며 시작품을 다양하게 제작하 여 시스템분석(shaker test)과 진동량 overall 값을 측 정하여 시작품을 평가하였다. 또한 본체와 쿨링홴의 체결부에 절연장치를 추가하여 쿨링홴에서 $\mathrm{PC}$ 로 전 달되는 진동성분을 흡수하도록 설계하였다. 동흡진장 치 및 절연장치를 설계하기 위하여 ansys를 이용한 유한요소 해석 결과를 활용하였다.

\section{2. 기존 쿨링홴의 가진원 분석}

\section{1 쿨링홴의 주요부품}

쿨링홴의 구성부품은 Fig. 1에서 보여주고 있다. 대상으로 한 쿨링홴은 본체용 쿨링홴으로 7 개의 날 개를 갖는 날개부, 4 개의 극수를 갖는 고정자, 본체 와 연결되는 case로 구성되어 있다. 회전하는 물체
의 날개 수와 모터의 극수는 편심이 존재할 경우 진동이 증폭되는 성분을 보여주는 것이 일반적이며 이와같은 쿨링홴의 주요부품에 대한 정보는 쿨링홴 의 진동량을 측정하여 가진원을 분석하는데 중요한 역할을 한다.

\section{2 쿨링홴의 가진원 분석}

쿨링홴의 진동/소음 저감을 위한 동흡진장치 및 절연장치를 설계하기 위하여 기존 쿨링홴의 가진원 을 분석하고 쿨링홴이 작동시 $\mathrm{PC}$ 의 진동량을 측정 하여 어떤 동특성이 나타나는지 파악하는 것이 중 요하다. Fig. 2는 실험을 위한 장치구성도를 나타내 고 있다. Tachometer로 쿨링홴의 회전속도를 측정 한 결과 정격상태인 $12 \mathrm{~V}, 0.17 \mathrm{~A}$ 에서 쿨링홴은 $2880 \mathrm{rpm}$ 으로 작동하였으며 실험조건을 고려하여 비접촉식 laser vibrometer를 사용하여 진동신호를 측 정하였다. 쿨링홴의 노후조건에 맞게 약 $2 \mathrm{~g}$ 의 편심 이 존재하는 정격상태에서 auto-spectrum을 측정한

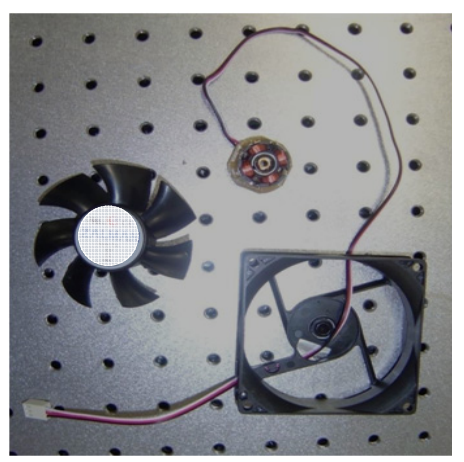

Fig. 1 Components of the cooling fan

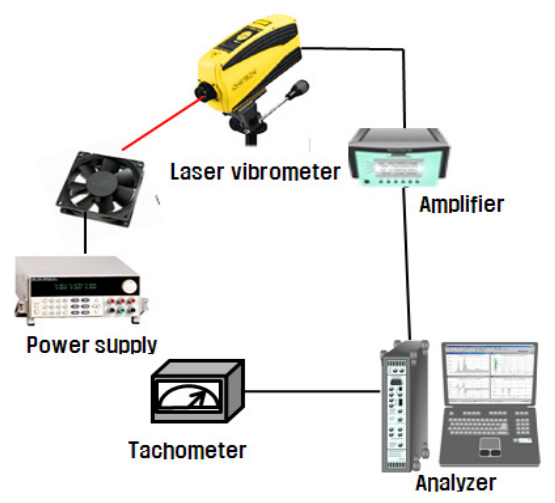

Fig. 2 Experimental setup for the overall analysis 
결과 Fig. 3에서와 같은 결과를 얻을 수 있었다. 주 파수분석 결과 홴의 1 차 회전성분 $48 \mathrm{~Hz}$ 와 모터의 극수에 의해 발생하는 4차 회전성분인 $192 \mathrm{~Hz}$ 에서 비교적 커다란 진동성분을 보이고 있다. 또한 730 $\mathrm{Hz}$ 와 $1281 \mathrm{~Hz}$ 에서도 많은 진동성분이 포함된 것을

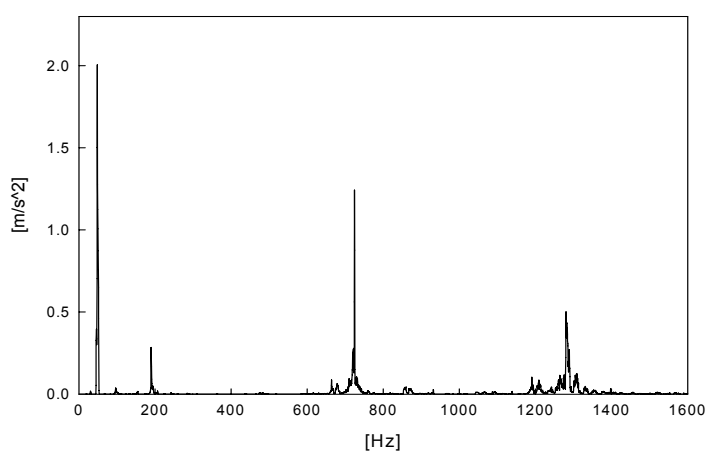

Fig. 3 The auto-spectrum of the cooling fan when operating speed is $2880 \mathrm{rpm}$

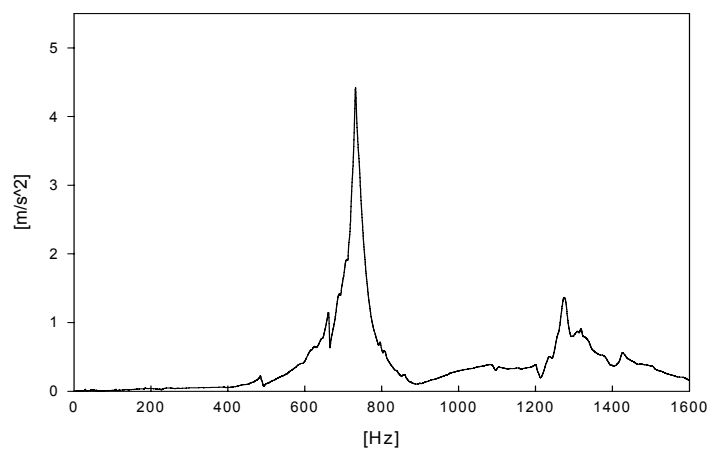

Fig. 4 The frequency response function of the cooling fan

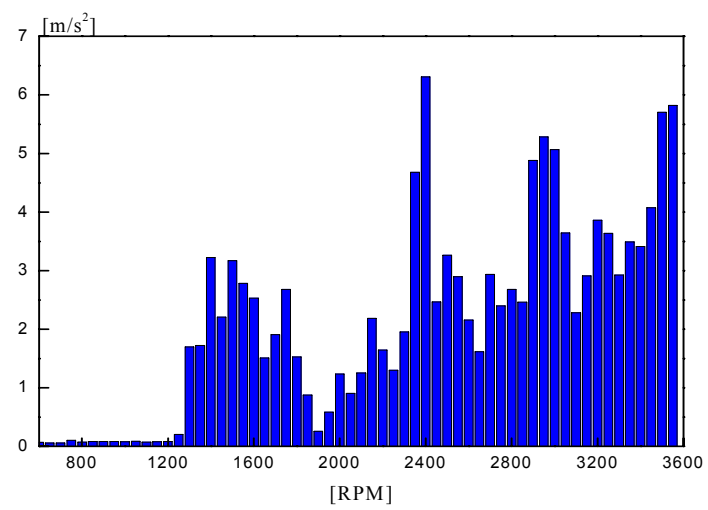

Fig. 5 Experimentally measured RMS of the PC
알 수 있는데 각 성분의 진동원인을 파악하기 위해 쿨링홴이 $\mathrm{PC}$ 에 체결된 상태에서 쿨링홴에 대하여 impact test를 실시하였으며 실험결과 Fig. 4에서 볼 수 있듯이 $732 \mathrm{~Hz}$ 와 $1276 \mathrm{~Hz}$ 에서 peak를 확인할 수 있으며 auto-spectrum 측정결과와 비교해 보면 $730 \mathrm{~Hz}$ 와 $1281 \mathrm{~Hz}$ 는 구조적인 공진에 의하여 발생 하는 것을 알 수 있다.

\section{$2.3 \mathrm{PC}$ 의 진동신호 측정}

쿨링홴의 과도한 진동은 $\mathrm{PC}$ 의 본체를 따라 전달 되며 옆면의 중앙부분에서 가장 커다란 진동이 발 생하게 된다. 따라서 쿨링홴의 회전속도에 따라 PC 의 진동량이 크게 발생하는 대역에서 진동을 저감 시키기 위한 동흡진장치 및 절연장치를 설계하기 위하여 power supply를 이용하여 쿨링홴의 회전주 파수를 $600 \mathrm{rpm}$ 에서 $3600 \mathrm{rpm}$ 까지 증가시키면서 $\mathrm{PC}$ 의 진동량 변화를 측정하였다. $\mathrm{PC}$ 의 진동은 Fig. 5 를 보면 2400 3600 rpm의 작동영역에서 상대적으 로 크게 발생하는 것을 알 수 있다. 그러므로 이 영 역에서 진동을 저감시키기 위한 동흡진장치를 설계 하고 $\mathrm{PC}$ 로 전달되는 진동을 흡수할 수 있는 절연 장치를 설계해야 한다.

\section{3. 유한요소 해석을 통한 설계변수 도출}

\section{1 동흡진장치 및 절연장치의 기본설계}

동흡진장치 및 절연장치의 기본설계를 실시하였 다. Fig. 6에서 볼 수 있듯이 동흡진장치는 질량역할 을 하는 황동과 스프링 및 댐퍼 역할을 하는 실리 콘으로 구성되어 있으며 쿨링홴의 좌우에 부착하는 방식이다. 또한 절연장치는 실리콘으로 이루어져 있 으며 본체와 쿨링홴을 결합시키며 진동이 전달되는 것을 차단하는 방식이다.

\section{2 동흡진장치 및 절연장치의 유한요소 해석}

기본설계안을 바탕으로 동흡진장치 및 절연장치 의 유한요소모델을 수립하였다. Fig. 7(a)와 같이 solid로 모델을 세우고 ansys를 이용하여 모달해석 을 수행한 결과 모드형상은 Fig. 7(b)와 같은 형태 이며 1차 모드의 고유진동수가 $47 \mathrm{~Hz}$ 를 보이고 있다. 마찬가지로 Fig. 8(a)와 같이 solid로 모델을 세우고 ansys를 이용하여 모달해석을 수행한 결과 모드형 상은 Fig.8(b)와 같은 형태이며 1차 모드의 고유 

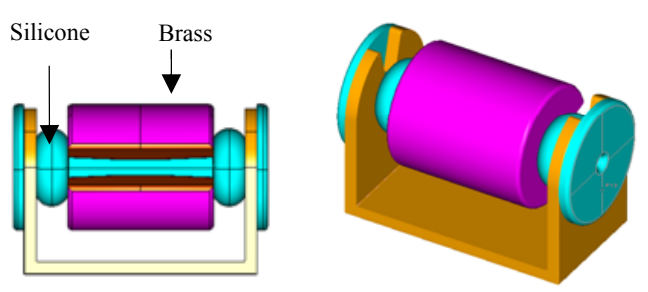

(a) Dynamic absorber

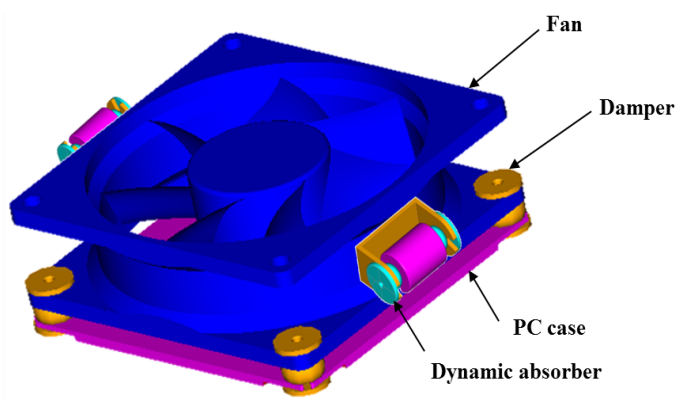

(b) Proposed system

Fig. 6 Proposed vibration absorbing system

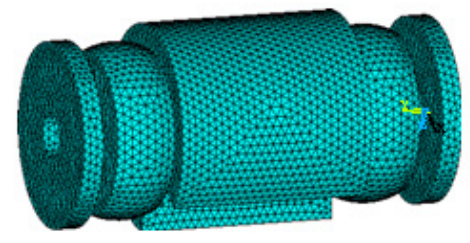

(a) Finite element model

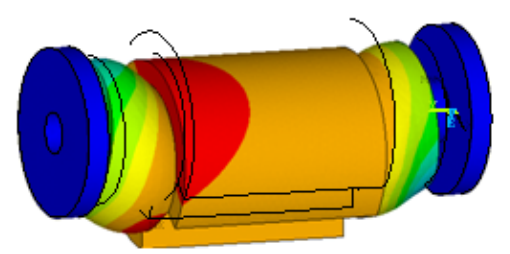

(b) $1 \mathrm{st}$ mode : $47 \mathrm{~Hz}$

Fig. 7 Finite element model and 1st vibration mode of dynamic absorber

진동수가 $57 \mathrm{~Hz}$ 를 보이고 있다. 시뮬레이션을 결과 를 바탕으로 목표로 한 특정주파수대역에 맞는 동 흡진장치 및 절연장치를 개발하기위한 설계변수를 도출하였다. 1차 고유진동수가 $45 \sim 60 \mathrm{~Hz}$ 범위내에 서 설계하여 시작품 제작시 황동과 크기, 질량, 실 리콘의 재료 등의 물성치를 다양하게 제작할 수 있 도록 설계하여 시작품을 제작하는데 반영하였다.

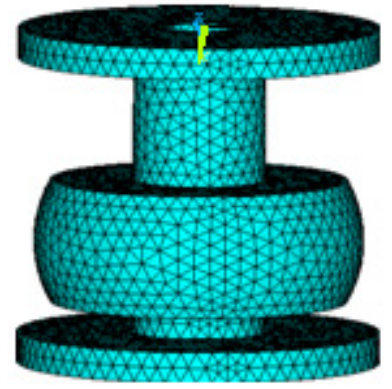

(a) Finite element model

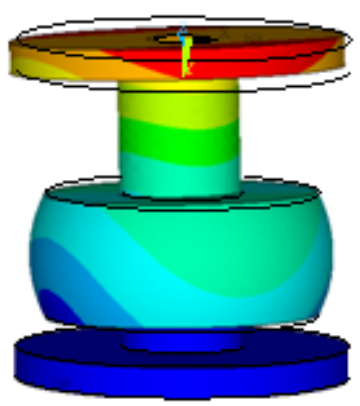

(b) $1 \mathrm{st}$ mode : $57 \mathrm{~Hz}$

Fig. 8 Finite element model and 1st vibration mode of damper

\section{4. 시작품 제작 및 실험적 검증}

\section{1 시작품 제작 및 검증방법}

유한요소 해석 결과를 통하여 도출한 설계변수를 바탕으로 시작품을 다양하게 제작하였다. Fig. 9는 동흡진장치와 절연장치 시작품의 실제 사진이다. 시 작품은 실험적으로 검증하였는데 시스템분석을 하 기위한 shaker test와 진동량을 측정하기 위한 overall analysis를 통하여 실시하였다. Fig. 10은 실 험평가를 위한 장치구성도이다.

\section{2 시작품의 실험적 검증}

시스템분석을 통하여 시작품의 1 차 고유진동수를 측정하고 쿨링홴에 시작품을 장착한 상태에서 $\mathrm{PC}$ 의 진동량을 측정하였다. Fig. 11은 동흡진장치와 절연 장치의 실험결과이며 1 차 고유진동수가 동흡진장치 는 $46 \mathrm{~Hz}$, 절연장치는 $56 \mathrm{~Hz}$ 이며 ansys를 통한 유 한요소 해석 결과와 유사한 것을 알 수 있다. Table 1 은 유한요소 해석 결과와 실험결과를 비교하기 위 한 표이다. 


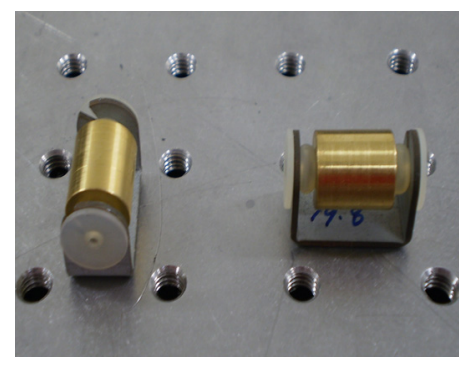

(a) Dynamic absorber

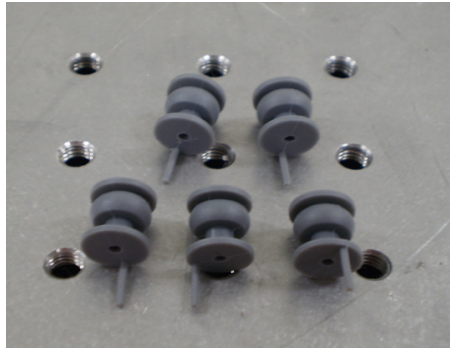

(b) Damper

Fig. 9 The trial products of vibration absorber and damper

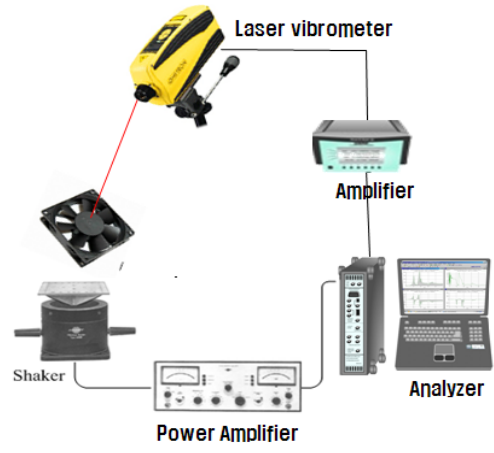

(a) Shaker test

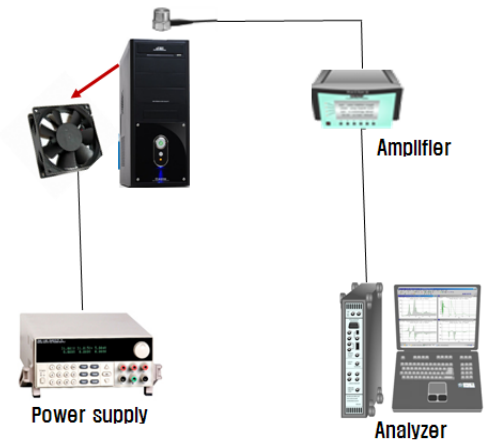

(b) Overall analysis

Fig. 10 Experimental setup for the test of trial products
Table 1 The results of FEM and system analysis

\begin{tabular}{c|c|c}
\hline \hline & FEM & System analysis \\
\hline Dynamic absorber & $47 \mathrm{~Hz}$ & $46 \mathrm{~Hz}$ \\
\hline Damper & $57.3 \mathrm{~Hz}$ & $56 \mathrm{~Hz}$ \\
\hline
\end{tabular}

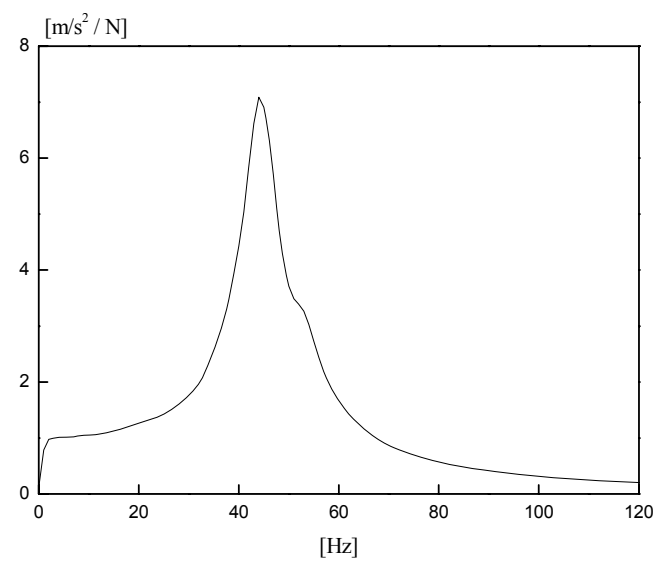

(a) Dynamic absorber $(48 \mathrm{~Hz})$

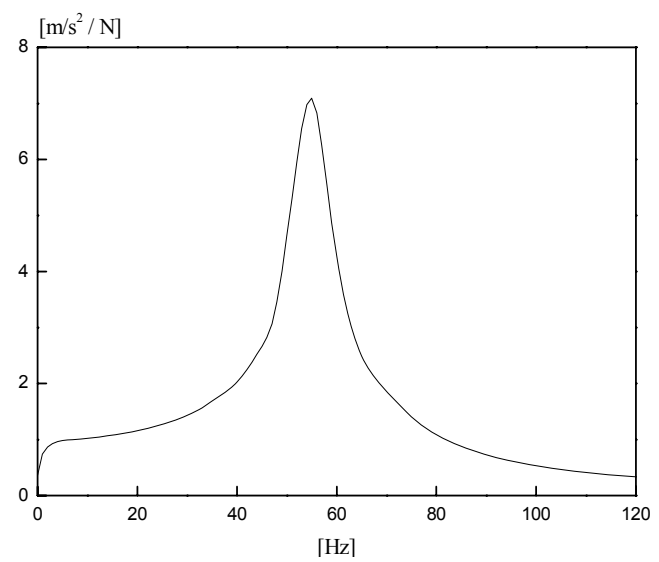

(b) Damper $(56 \mathrm{~Hz})$

Fig. 11 Acceleration autospectrums of dynamic absorber and damper obtained from shaker test

시작품을 쿨링홴에 장착한 상태에서 $\mathrm{PC}$ 의 진동 량을 측정하여 시작품을 평가하였다. Fig. 12는 실 험결과를 동흡진장치 및 절연장치가 없는 경우와 함께 보여주고 있는데 비교결과 진동을 저감하고자 했던 작동대역에서 커다란 진동저감효과를 확인하 였다. 다만 $1400 \mathrm{rpm}$ 의 낮은 회전속도에서 $0.5 \mathrm{~m} / \mathrm{s}^{2}$ 정도의 진동이 증가하는 것을 볼 수 있는데 이는 쿨링홴을 볼트로 채결했을 때 보다 다소 헐거워진 구속조건 때문에 발생하는 것으로 판단되며 동흡진 


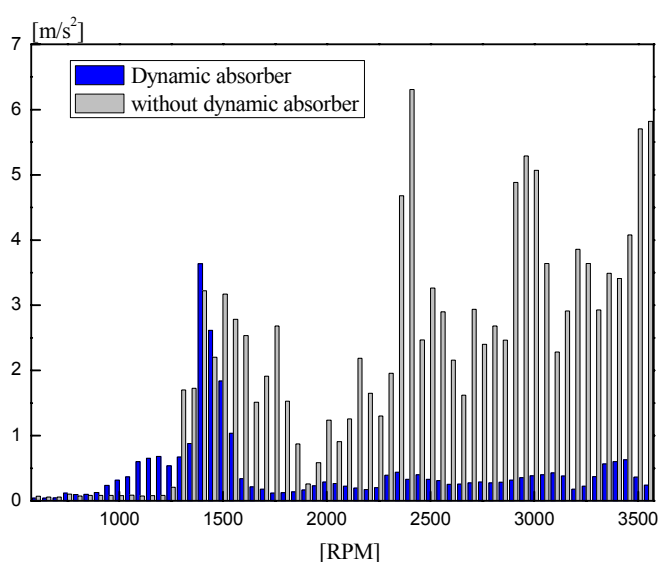

Fig. 12 Experimentally measured RMS of the PC with trial product

Table 2 The RMS values of the PC with $200 \mathrm{rpm}$ interval

\begin{tabular}{c|c|c}
\hline \hline Speed(rpm) & Existing models $\left(\mathrm{m} / \mathrm{s}^{2}\right)$ & Trial model $\left(\mathrm{m} / \mathrm{s}^{2}\right)$ \\
\hline 800 & 0.074 & 0.093 \\
\hline 1000 & 0.078 & 0.316 \\
\hline 1200 & 0.084 & 0.677 \\
\hline 1400 & 3.220 & 3.635 \\
\hline 1600 & 2.532 & 0.337 \\
\hline 1800 & 1.527 & 0.123 \\
\hline 2000 & 1.233 & 0.289 \\
\hline 2200 & 1.647 & 0.174 \\
\hline 2400 & 6.307 & 0.331 \\
\hline 2600 & 2.157 & 0.252 \\
\hline 2800 & 2.681 & 0.278 \\
\hline 3000 & 5.067 & 0.382 \\
\hline 3200 & 3.858 & 0.177 \\
\hline 3400 & 3.411 & 0.602 \\
\hline Average & 2.154 & 0.445 \\
\hline & & \\
\hline
\end{tabular}

장치 및 절연장치의 설계대역에서 진동저감효과와 쿨링홴이 정상작동시 $2880 \mathrm{rpm}$ 으로 구동되는 것을 감안하면 타당한 결과라고 할 수 있다. 정상작동상 태에서 $200 \mathrm{rpm}$ 간격으로 진동량을 측정한 결과를 Table 2 를 통해 정리하였다. 전체의 평균을 계산해 본 결과 기존모델의 경우에는 $2.154 \mathrm{~m} / \mathrm{s}^{2}$ 의 진동량 을 나타내었으나 시작품을 장착하고 $0.445 \mathrm{~m} / \mathrm{s}^{2}$ 의 진동량을 나타내어 $60 \%$ 이상의 커다란 진동저감

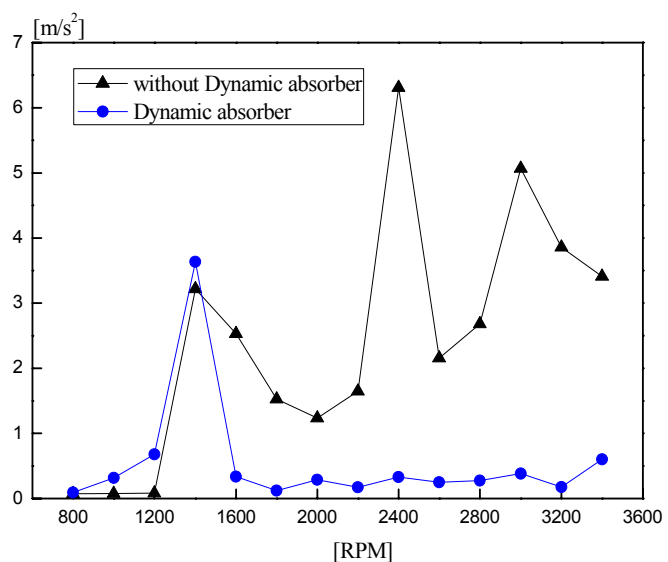

Fig. 13 The RMS values of the PC with $200 \mathrm{rpm}$ interval

Table 3 The vibration and noise level at $2880 \mathrm{rpm}$

\begin{tabular}{c|c|c}
\hline \hline & Existing models & Trial model \\
\hline Vibration $\left(\mathrm{m} / \mathrm{s}^{2}\right)$ & 2.461 & 0.283 \\
\hline Noise level $(\mathrm{dBA})$ & 71 & 61 \\
\hline
\end{tabular}

효과를 보여주고 있으며 Fig. 13은 Table 2를 도식 화 한 것이다.

최종적인 평가를 위하여 시작품을 장착하고 정격 상태인 $12 \mathrm{~V}, 0.17 \mathrm{~A}$ 에서 쿨링홴이 $2880 \mathrm{rpm}$ 으로 구동될 경우의 진동량 및 소음레벨을 측정하였다. 소음레벨은 $\mathrm{PC}$ 에서 $1 \mathrm{~m}$ 떨어진 위치에서 소음계를 사용하여 반복측정 하였다. 실험결과는 기존모델과 시작품을 장착하였을 경우를 비교하여 Table 3에 나 타내고 있는데 진동량의 경우 $80 \%$ 이상, 소음레벨 은 $10 \mathrm{~dB}$ 정도의 저감효과를 알 수 있다.

\section{5. 결 론}

이 연구에서는 $\mathrm{PC}$ 의 진동 및 소음저감을 위한 쿨링홴의 동흡진장치 및 절연장치를 개발하였다. 쿨 링홴의 가진원을 분석하고 구조적인 문제점을 확인 하여 저감시키고자 하는 관심주파수를 선정하였다. 또한 대상의 유한요소 해석 모델을 세워 설계변수 를 도출하고 관심주파수영역 내에서 진동을 저감시 킬 수 있는 동흡진장치 및 절연장치를 설계하였다. 다양한 시작품의 제작과 반복적인 실험과정을 통하 여 $\mathrm{PC}$ 의 진동 및 소음을 저감할 수 있는 시스템을 
개발할 수 있었다. 이 연구결과는 향후 쿨링홴과 같 이 회전하는 구조물의 편심에 의하여 발생되는 진 동저감을 위하여 적용될 수 있을 것이다.

\section{후 기}

이 논문은 중소기업청에서 지원하는 2008년도 산 학연공동기술개발사업(08-c1-08-914)의 연구수행으로 인한 결과물임을 밝힙니다. 이에 감사드립니다.

\section{참 고 문 헌}

(1) Chung, J. T., 2004, Vibration Absorber for Reduction of the In-plane Vibration in an Optical Disk Drive, IEEE Transactions on Consumer Electronics, Vol. 50, No. 2, pp. 552 557.

(2) Heo, J. W., Chung, J. T. and Park, J. M., 2002, Vibration and Noise Reduction of an Optical Disk Drive by Using a Vibration Absorber, IEEE Transactions on Consumer Electronics, Vol. 48, No. 4, pp. 874 878.

(3) Chung, J. T., Park, J. M. and Ro, D. S., 1997, Optimal Position of the Dampers in a CD-ROM Drive to Remove the Tilting Vibration Mode, Journal of Sound and Vibration, Vol. 7, No. 3, pp. 393 399.
(4) Kim, N. W., Kim, K. W. and Sin, H. C., 2007, A Design of a Dynamic Vibration Absorber for a DVD +/- RW Drive, IEEE Transactions on Consumer Electronics, Vol. 53, No. 3, pp. 956 961.

(5) Park, C. H., Song, S. H., Shin, H. J. and Hong, S. C., 1993, A Study on the Behaviour of Nonlinear Dynamic Absorber, Transactions of the Korean Society for Noise and Vibration Engineering, Vol. 3, No. 2, pp. 137 143.

(6) Kim, K. W., Kim, N. W., Lim, J. R. and Ahn, T. K., 2001, Dynamic Characteristics Prediction of Rubber Mounts for Anti-vibration of an Optical Disk Drive, Journal of the Korean Society of Precision Engineering, Vol. 18, No. 12, pp. 104 109.

(7) Bae, C. H., Cho, C. W., Yang, K. H. and Park, Y. P., 2001, Vibration Reduction by Dynamic Absorber of Vertical Pump System, Proceedings of the KSNVE Autumn Annual Conference 2001, pp. 628 632.

(8) Chung, J. T. and Kim, W. H., 2009, A Study on the Characteristic of Noise and Vibration in 3-phase Induction Motor for the Forklift, Transactions of the Korean Society for Noise and Vibration Engineering, Vol. 19, No. 1, pp. 3 9. 